\title{
Use of Nano Cutting Fluid in Machining
}

\author{
[Sleman Rasul, Nihat Tosun, Sarkawt Rostam]
}

\begin{abstract}
Nano cutting fluids are the mixture of conventional cutting fluid and nanoparticles. Addition of the nanoparticles can alter wettability and lubricating properties. This paper presents a comprehensive review of published research works on the use of nano fluids in machining processes. Nano cutting fluid plays an important role in minimizing production time, cost and energy in different machining operations. The study covers the classification of nano fluids and their effect on both workpiece and cutting tools including surface roughness, tool wear and cutting force has been explained. As a result, the paper presents a roadmap for the researchers and practitioners during the utilization of nano cutting fluids in machining processes.
\end{abstract}

Keywords - Nano fluid, machining performance.

\section{Introduction}

There are new classes of fluids called nano fluids which are contrived by separating nanometer-sized materials (nanoparticles, nanofibers, nanotubes, nanorods, nanosheet and droplets) in base fluids [1]. In addition, nanofluids are nanoscale colloidal suspensions holding solid nanomaterials. It consists of two phase systems solid phase and liquid phase and for a two-phase system we have to face some important issues [2]. The most important nano cutting fluid application in machining issue is the solidity of nanofluids and it is a big challenge to attain a desired solidity of nano fluids [3]. Recently, Nanofluids attracted more attention of people due to its importance in all aspects of life and its wide range of application though some research articles including the progress of nano fluids published the majority of researches are related to experimental and theoretical studies of the thermo physical properties or the convective heat transfer of nano fluids $[4,5]$.

Sleman Yahya Rasul

Firat University, Engineering Faculty, Mechanical Engineering Department Elazig, Turkey

Nihat Tosun

Tunceli University, Engineering Faculty, Mechanical Engineering Department

Tunceli, Turkey
New application trends for nano fluids was studied and related to the heat transfer properties of nano fluids [6]. The size of nanoparticles (usually less than 100nm) in liquids mixture gives them the capacity to interact with liquids at the molecular level and so conduct heat better than today's heat transfer fluids depending on nanoparticles. In order to retain enhanced thermophysical properties metallic nano fluids have been found such as thermal conductivity, thermal diffusivity, viscosity and convective heat transfer coefficients compared to those of base fluids like oil or water. Now days the importance of nanofluids increased in many fields like solar collector and solar thermal storage [79].

Nano fluids show better steadiness and rheological properties, higher thermal conductivity, and no penalty in pressure drop when compared with suspended particles of millimeter-or micrometer dimensions. This new composite fluid is very important and lack of research and information has not been noticed by researchers that include preparing and solidity issues of nanofluids, expectations of thermal conductivity of nanofluids accurate for industrial condition. Prediction of viscosity of nanofluids for industrial condition with heat transfer fluid are important some aspects [10]. It is clear that we need extensive studies in a variety of fields due to the existence of industrial development and requests of new procedures for improving production process. Producers are always looking for higher yields and incomes. Actually the main goal in producing is to minimize the production time, cost, energy and resources along with improving the function $[6,11]$. In this way cutting fluids play an important role. Cutting fluid has a vital role in this way that's why metalworking fluids prevent from metal to metal contact and reduce internal friction [12]. In metal working operations, the fictional resistance can be reduced by adding a lubricant between the surfaces. Lubricants divide the sliding surfaces by creating a film and decrease the fictional resistance and wearing [13]. The ability to cool a fluid helps to control undesirable temperature of tool, workpiece and chip. In addition when processing cutting fluid can wash and remove generated chip. We can use cutting fluids to avoid re-welding, corrosion, reducing the amount of energy of the machine and increasing tool life [14]. During the operation of cutting a metal, the cutting fluid functions in three ways: cools the workpiece surface and the cutting tool, removes the chips from the cutting zone and lubricate the tool workpiece interface [15]. It was perceived that the application of cutting fluids during machining facilitates economy of tools, maintains tight tolerance, and keeps the surface properties safe from damages. It was realized that the use of cutting fluids has negative impacts on human health and the environment both through their use and their disposal. Also, the cutting fluid occupies 16-20\% of the cost of production in the manufacturing industry. Therefore, excessive use of these fluids (flood lubrication) should be avoided [16]. 
The complex process is machining where the cutting tool wear is caused by the interaction of high temperature, friction and load. These limitations can led to mechanical, adhesive dissuasive thermal and chemical wears of the cutting tool. Some of these limitations can dominate according to the cutting performance and material of the cutting edge and the machined material [17,18]. Despite their many advantages, cutting fluids possess major drawbacks. They generate additional costs, price itself and the need of their disposal [19-21].

This paper presents a comprehensive review of nano fluid applications in machining and the role of nano fluids in increasing the machining performance and hence the product quality. The reminder of the paper is organized as follows. Section 2 presents classification of nano fluids. The effects of nano fluid on both workpiece and cutting tool showed in Section 3 followed by the difficulties of applying nano fluids in machining in Section 4. Conclusions are summarized in the last section.

\section{Classification of nano fluids}

There two categories of nano fluids; metallic nano fluids and non-metallic nano fluids. According to theoretical atomic and micro scale-level characteristic behavior of nano fluids, it shows that the enhancement of thermal conductivity, temperature dependent effects and significant raise in critical heat flux. By Metallic nanofluids we mean containing metallic nanoparticles such as $(\mathrm{Cu}, \mathrm{Al}, \mathrm{Zn}, \mathrm{Ni}, \mathrm{Si}$, $\mathrm{Fe}, \mathrm{Ti}, \mathrm{Au}$ and $\mathrm{Ag}$ ), while nanofluids containing nonmetallic nanoparticles such as aluminium oxide $\left(\mathrm{Al}_{2} \mathrm{O}_{3}\right)$, copper oxide $(\mathrm{CuO})$ and silicon carbide $\left(\mathrm{SiC}, \mathrm{ZnO}, \mathrm{TiO}_{2}\right)$ are often considered as non-metallic nanofluids, semiconductors $\left(\mathrm{TiO}_{2}\right)$, Carbon Nanotubes (SWCNT, DWCNT and MWCNT) and composites materials such as nanoparticles core polymer shell composites. Furthermore, materials and structure are attractive for use in nanofluids where the particle liquid interface is doped with various molecules [22-25].

An important nano cutting fluid application in machining consideration in the application of nano fluids is viscosity such as a lubricant or heat transfer fluids. Empirical investigations into the viscosity of nanofluids show limitations in the existing theories, models and correlations [26]. The parameters which have been applied so far in modeling nanofluid viscosity include volume fraction or concentration, temperature, packing fraction, thickness of the nanolayer, particle shape/aspect ratio, aggregate radius, inter-particle spacing and the capping layer. In addition the behavior of disperse magnetic nanofluids is of interest in the design of engineering systems requiring induced magnetic field effects for optimum performance. Therefore, the effective viscosity behavior of magneto-rheological nanofluids (MRNF) is principally governed by the presence of a magnetic field $[27,28]$.

\section{Effect of nanofluid on workpiece and cutting tools}

\section{A. Surface roughness}

While applying nanofluid as coolant, the quality of machining surface is better than dry condition or any other types of conventional fluids [29]. When it is dry, due to lack of cutting fluid, the wear of cutting edge appears soon, so the process will be (rougher) and the (Ra) generated on the metal surface will be high (Figure 1) [30]. During machining with suitable amount of cutting fluid, it preserves the cutting edge because of its cooling and lubricating properties, so the Ra generated will be better than its range in dry machining and machining process remains partially smooth [31,32]. The main role of nano-cutting fluid is to improve the wetting equal lubricating properties of rake and flank areas. Better heat dissipation results from the net effect, so the machining process is smoother and results in retaining of hardness of the tool cutting edge. During machining with nanofluid, the roughness of the surface is minimum as compared to the other machining condition (Figure 1) [2,33].

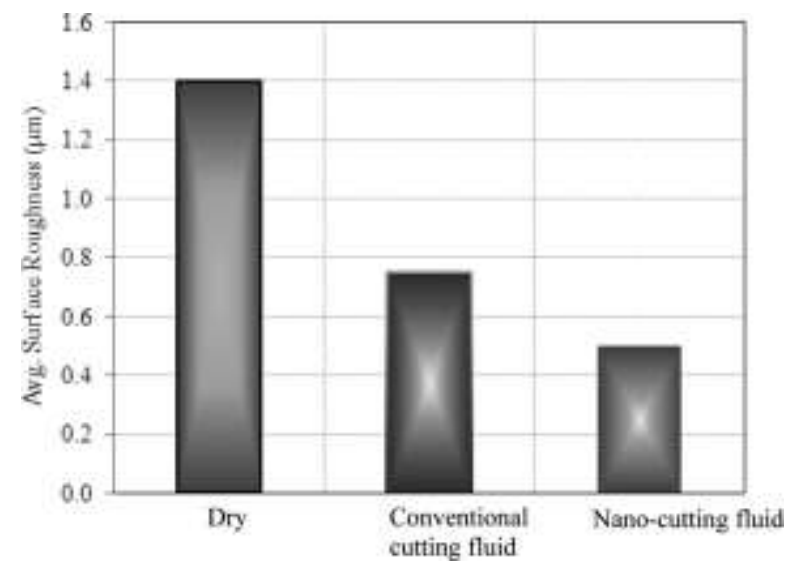

Fig 1. Effect of different fluids on surface roughness [7]

\section{B. Tool Wear}

Another significant parameter which has direct effect on the final quality of the product is tool wear. It also influences the performance of the tool and tool life. Tool wear is the main factor of the tool failure during the process it totally limits the performance of the cutting process, there are several factors that result in tool wears, but abrasion, adhesion and diffusion are caused by the high temperature of the tool-chip interface $[13,34]$. It need to be taken into consideration that tool wear influences the machining economy and early wear leads to uneconomic machining, it has been studied that the rate of tool abrasion can be reduced by proper lubricity and excellent cooling abilities of the nano fluid [35]. According to recent studies, tool wears means morphology of crater and flank wear. The tool material wear is affected by the temperature generated in the primary and secondary shear zone, the availability of high cutting temperature and the cutting edge stress, together with the tool materials brittleness, increases the chipping, cracking and the tool inserts fracture [36,37]. This can be often seen in dry machining operation, which is resulted 
from the absence of cutting fluid, and also crater wear will be higher. Severe flank wear is caused by the absence of cutting fluid and continuous rubbing of the machined work surface on the thermally softened flank face, as compared to dry condition suitable amount of cutting fluids supply lubrication and partially decrease the generated heat in machining area but dominate adhesive wear mode causes create wear near the cutting edge of the tool [24,38]. The mechanism of adhesive wear depends on the followings, the hot strength of the tool materials at the adhesive junction, adhesive affinity of the tool and workpiece and the frequency of interruptions at the adhesive contact [39]. Severe adhesion wear is increasingly resulted from wear interface bonding between tool-workpiece surfaces the layer of the adhered workpieces surface often is attached to the tool edge, thus the create wear occurs at the machining seizure zone [40]. Continuous rubbing of workpiece with the flank face tries to chip-off the layers of the tool flank surface. The tool retains its hardness due to suitable cutting fluid lubrication ability and so flank wear partly reduces as compared to dry process $[41,42]$. In case of nano cutting fluid, both create and flank wear decrease hugely and the reasons behind this are its convectional, conduction and wettability because of both better cooling and lubrication properties of nano cutting fluid [43]. The tool maintains its hardness for longer times. Thus the flank wear amount will be minimal as compared to the other two processes $[44,45]$.

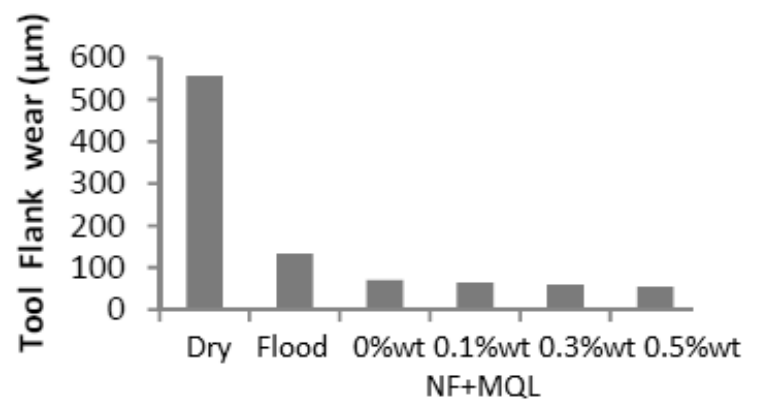

Fig 2. Effect of different fluids on tool wear [45]

\section{Cutting force}

According to the investigations, cutting forces decrease and more than that the forces will rise to some extent with increase in concentration of nanoparticles up to a particular level [46]. Cutting force during milling by MQL method (with pure water and water and water includes nano particles) have been compared to each other [47]. Due to the chart, not only the existence of nanoparticle in base fluid, but also type, size and concentration of nanoparticles are effective on cutting forces. For example, water $\mathrm{A}_{2}{ }_{2} \mathrm{O}_{3}$ nano fluid with 2.5 vo $1 \%$ leads to increase in forces. This event is due to forming a dense and hard slurry layer in high concentrations of $\mathrm{A}_{2} \mathrm{O}_{3}$ (4 vole \%), therefore grinding forces will increase $[48,49]$.

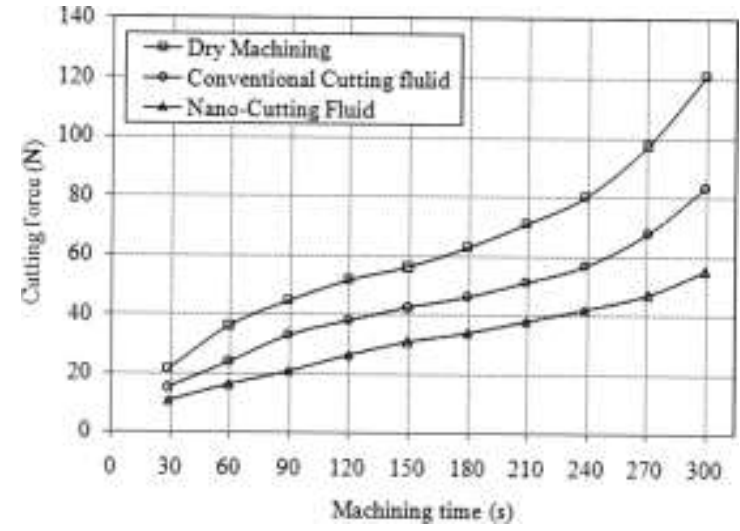

Fig 3. Effect of different fluids on cutting force [7]

\section{Conclusions}

In the last few decades, some papers declared the great roles of nano cutting fluid in machining. The current research work presented a comprehensive review of using nano fluids in machining. Some papers present that not only using nano fluids influence on nano cutting fluid machining parameters but the size, type of nanoparticle, and concentration of particles in base fluid are crucial. But most of the experimental researches announced that tribological properties developed with raising concentration of nanoparticles in base fluid. Even though, this paper illustrates an overview of typical developments in the study of nano cutting fluid application in machining, including the stability mechanisms, the evaluation methods for their stability, the potential applications in heat transfer intensification, better heat transfer, energy field, preparation methods, and mass transfer enhancement. Results showed that if they are used in a perfect way, due to change in lubrication trait, physical characteristics (viscosity, thermal conductivity, density, and thermal capacity) better heat transfer rate will be observed. According to literature review, the nano-enriched cutting fluid exhibits better tribological properties compared to its base fluid. The following key issues should receive better attention in the coming future to enrich the use of nano cutting fluid application in machining. Firstly, experimental and theoretical researches are required to find the main characters affecting the performance of nano fluids. Up to now, there is a lack of agreement between experimental results from different groups, so it is very important to systematically identify these factors. The detailed and accurate structure characterizations of the suspensions may be the key to elucidate the contrast in the experimental data. Secondly, the shape of additives in nano fluids is very important for the properties, therefore the new nano fluid synthesis approaches with controllable microscope structure will be an interesting research work. Thirdly, stability of the suspension is an important issue for both scientific research and practical applications. The stability of nano fluids, especially the long term stability, the stability in practical conditions and the stability after thousands of thermal cycles should be taken into consideration. Fourthly, increase in viscosity by the use of nano fluids is an important drawback due to the associated increase in pumping power. The applications for nano fluid with low viscosity and high conductivity are promising. In conclusion, utilizing nano 
cutting fluid application in machining as coolant and lubricant lead to lower tool temperature, tool wear, high surface quality, cutting force, specific energy, surface roughness, and torque in drilling and less environmental dangers. However, high cost of nano particles, need for particular devices, clustering and sediment are negative aspects of nano fluid applications in metal working operations.

\section{References}

[1] Eastman J.A., Phillpot S.R., Choi S.U:S, Keblinski P., "Thermal transport in nanofluids", Annual Review of Materials Research, 34 219-246, 2004

[2] Siginer, D.A., Wang H.P., "Developments and applications of NonNewtonian flows Developments and Applications of Non-Newtonian Flows 1995: International Mechanical Engineering Congress and Exposition", American Society of Mechanical Engineers (FED), California, November 12-17, 1995.

[3] Cui X., Zhao J., Dong Y., "The effects of cutting parameters on tool life and wear mechanisms of CBN tool in high-speed face milling of hardened steel", International Journal of Advanced Manufturing Technology, 66, 955-964, 2013.

[4] Shokrani A., Dhokia V., Newman S.T., "Environmentally conscious machining of difficult-to-machine materials with regard to cutting fluids", International Journal of Machine Tools and Manufacture, 57, 83-101, 2012.

[5] Kishawy, H.A., Dumitrescu, M., Ng, E.G., Elbestawi, M.A., "Effect of coolant strategy on tool performance, chip morphology and surface quality during high speed machining of A356 aluminum alloy", International Journal of Machine Tools and Manufacture, 45, 219-227, 2005.

[6] Kakaç S., Pramuan jaroenkij A., "Review of convective heat transfer enhancement with nanofluids, International Journal of Heat and Mass Transfer, 52, 3187-3196, 2009.

[7] Khandekar S., Ravi Sankar M., Agnihotri V., Ramkumar J., "NanoCutting Fluid for Enhancement of Metal Cutting Performance", Materials and Manufacturing Processes, 27: 963-967, 2012.

[8] Das S.K., Putra N., Thiesen P., Roetzel W., "Temperature dependence of thermal conductivity enhancement for nanofluids", ASME Journal of Heat Transfer, 125, 567-574, 2003.

[9] Patel H.E., Das S.K., Sundararajan T, Nair A.S., George B., Pradeep T., "Thermal conductivity of naked and monolayer protected metal nanoparticles based nanofluids: Manifestation of anomalous enhancement and chemical effects", Applied Physics Letters, 83, 2931-2933, 2003.

[10] Wang X.Q., Mujumdar A.S., "A review on nanofluids part I: theoretical and numerical investigations", Brazilian Journal of Chemical Engineering, 25(4), 613-630, 2008.

[11] Saidur R., Leong K.Y. and. Mohammad H.A., "A review on applications and challenges of nanofluids", Renewable and Sustainable energy reviews, 15, 1646-1668, 2011 .

[12] Neugebauer R., Drossel W., Wertheim R., Hochmuth C., Dix M., "Resource and energy efficiency in machining using highperformance and hybrid processes", Procedia CIRP, 1, 3-16, 2012.

[13] Shokoohi Y., Khosrojerdi E., Shiadhi RB.H., "Machining and ecological effects of a new developed cutting fluid in combination with different cooling techniques on turning operation", Journal of Cleaner Production, 94, 330-339, 2015.

[14] Wong K.V., Leon O.D.., "Applications of Nanofluids: Current and Future, Advances in Mechanical Engineering, 2010, 1-11, 2010.

[15] Heris S.Z., Esfahany, M.N., Etemad, S.G. "Experimental investigation of convective heat transfer of $\mathrm{Al} 2 \mathrm{O} 3$ / water nanofluid in circular tube", International Journal of Heat and Fluid Flow, 28, 203-210, 2007.

[16] Yan L., Yuan S., Liu Q. "Influence of minimum quantity lubrication parameters on tool wear and surface roughness in milling of forged steel", Chinese Journal of Mechanical Engineering, 25, 419-429, 2012.

[17] Khan A.A., Ahmed M.I. "Improving tool life using cryogenic cooling”, Journal of Materials Processing Technology, 196, 149-154, 2008.

[18] Bermingham M., Palanisamy S., Kent D., Dargusch M.S., "A comparison of cryogenic and high pressure emulsion cooling technologies on tool life and chip morphology in Ti-6Al-4V cutting", Journal of Materials Processing Technology, 212, 752-765, 2012.

[19] Vamsi K. P., Nageswara R. D., "Performance evaluation of solid lubricants in terms of machining parameters in turning", International Journal of Machine Tools and Manufacture, 48, 11311137,2008

[20] Anuj K.S., Arun K.T., Amit R.D., "Progress of nanofluid application in machining", Materials and Manufacturing Processes, 30, 813-828, 2015.

[21] Dhar N.R., Islam M.W., Islam S. Mithu M.A.H. "The influence of minimum quantity lubrication (MQL) on cutting temperature, chip and dimensional accuracy in turning AISI 1040 steel". Journal of Materials Processing Technology, 171, 93-99, 2006.

[22] Lo C.H., Tsung T.T., Chen L.C. "Shape-controlled synthesis of Cubased nanofluid using submerged arc nanoparticle synthesis system (SANSS)", Journal of Crystal Growth, 277(1-4), 636-642, 2005.

[23] Sreejith P.S., Ngoi B.K.A. "Dry machining: Machining of the future", Journal of Materials Processing Technology, 101, 287-291, 2000.

[24] Yu W., Xie H., "Review on nanofluids: preparation, stability mechanisms, and applications". Journal of Nanomaterials, 1-17, 2012.

[25] Ozerinc S., Kakac S., Yazicioglu A.G., "Enhanced thermal conductivity of nanofluids: a state-of-the-art review", Microfluidics and Nano fluidics, 8, 145-170, 2010.

[26] Otanicar T., Hoyt J., Fahar M., Jiang X., Taylor R.A., "Experimental and numerical study on the optical properties and agglomeration of nanoparticle suspensions," Journal of Nanoparticle Research, 15, 2039-2050, 2013

[27] Murshed S.M.S, Leong K.C., Yang C., Investigations of thermal conductivity and viscosity of nanofluids, International Journal of Thermal Sciences, 47, 560-568, 2008.

[28] Yang L., Du K., Zhang X. S., Cheng B., "Preparation and stability of $\mathrm{A} 12 \mathrm{O} 3$ nano-particle suspension of ammonia-water solution", Applied Thermal Engineering, 31, 3643-3647, 2011.

[29] Saravanakumar N., Prabu L., Karthik M., Rajamanickam A., "Experimental analysis on cutting fluid dispersed with silver nano particles", Journal of Mechanical Science and Technology, 28, 645651, 2014.

[30] Li Q., Yimin X., "Convective heat transfer and flow characteristics of Cu-water nano-fluid", Science in China (Series E), 45 (4), 408416, 2002.

[31] Shen B., Shih A.J., Tung S.C. "Application of nanofluids in minimum quantity lubrication grinding", Tribology Transactions, 51, 730-737, 2008

[32] Vasu V., Reddy G.P.K., "Effect of minimum quantity lubrication with Al2O3 nanoparticles on surface roughness, tool wear and temperature dissipation in machining Inconel 600 alloy", Proceedings of the Institution of Mechanical Engineers, Part N: Jour. Nanoengg. Nanosys. 225, 3-16, 2011.

[33] Vasu V., Kumar K.M., "Analysis of nanofluids as cutting fluid in grinding EN-31 steel”, Nano-Micro Letters, 3, 209-214, 2011 
[34] Shashidhara Y.M., Jayaram S.R., "Vegetable oils as a potential cutting fluid—an evolution", Tribology International, 43, 1073-1081, 2010 .

[35] Weinert K., Inasaki I., Sutherland J., Wakabayashi T., "Dry machining and minimum quantity lubrication", CIRP Annals Manufacturing Technology, 53, 511-537, 2004.

[36] Sodavadia K., Makwana A, "Experimental investigation on the performance of coconut oil based nano fluid as lubricants during turning of AISI 304 austenitic stainless steel", International Journal of Advanced Mechanical Engineering, 4, 55-60, 2014.

[37] Nouari M., List G., Girot F., Coupard D., "Experimental analysis and optimization of tool wear in dry machining of aluminum alloys,' Wear, 255, 1359-1368, 2003.

[38] Srikant R., Rao D., Subrahmanyam M., Krishna V.P., “Applicability of cutting fluids with nanoparticle inclusion as coolants in machining", Proc. Ins. Mech. Eng., Part J: J. Eng. Trib., 223, 221225, 2009.

[39] Sayuti M., Sarhan A. A. D., Tanaka T., "Cutting force reduction and surface quality improvement in machining of aerospace duralumin AL-2017-T4 using carbon onion nanolubrication system", The International Journal of Advanced Manufacturing Technology, 65, 1493-1500, 2013.

[40] Prasad M.M.S., Srikant R.R, "Performance evaluation of nano graphite inclusions in cutting fluids with MQL technique in turning of AISI 1040 steel", International Journal of Research in Engineering and Technology, 2, 381-393, 2013.

[41] Kurniawan D., Yusof N.M., Sharif S., "Hard machining of stainless steel using wiper coated carbide: Tool life and surface integrity", Materials and Manufacturing Processes, 25 (6), 370-377, 2010.

[42] Otanicar T., Phelan P.E., Prasher R.S., Rosengarten G., Taylor R.A., "Nanofluid-based direct absorption solar collector", Journal of Renewable and Sustainable Energy, 2, 033102., 2010.

[43] Tyagi H., Phelan P., Prasher R., "Predicted efficiency of a lowtemperature Nanofluid-based direct absorption solar collector", Journal of Solar Energy Engineering, 131(4), 041004, 2009.

[44] Wang B., Wang X., Lou W., Hao J., "Rheological and tribological properties of ionic liquid-based nanofluids containing functionalized multi-walled carbon nanotubes", Journal of Physical Chemistry C, 114(19), 8749-8754, 2010.

[45] Amrita M., Srikant R.R., Sita Rama Raju A.V., "Performance Evaluation and Economic Analysis of Minimum Quantity Lubrication with Pressurized/Non-Pressurized Air and Nanofluid Mixture", International Journal of Mechanical, Aerospace, Industrial, Mechatronic and Manufacturing Engineering, 9(6), 996-1001, 2015.

[46] Khalil A.N.M, Ali M.A.M, Azmi A.I., "Effect of Al2O3 nanolubricant with SDBS on tool wear during turning process of AISI 1050 with minimal quantity lubricant", Procedia Manufacturing, 2, 130 - 134, 2015.

[47] Rahmati B., Sarhan A.A., Sayuti M., "Investigating the optimum molybdenum disulfide (MoS2) nanolubrication parameters in $\mathrm{CNC}$ milling of AL6061-T6 alloy", The International Journal of Advanced Manufacturing Technology, 70.1143-1155., 2014

[48] Alinejad Gh., Ghafari M., "Principles of universal machining machine tool", Babol University Technology press, Babol, Iran., 2011.

[49] Enomoto T., Sugihara T., "Improving anti-adhesive properties of cutting tool surfaces by nano-/micro-textures", CIRP Annals Manufacturing Technology, 59, 597-600, 2010. 